\title{
A study on the relationship between mouth breathing and facial morphological pattern
}

\author{
Ana Paula Bianchini', Zelita Caldeira Ferreira \\ Guedes $^{2}$, Marilena Manno Vieira ${ }^{3}$
}

Key words: mouth breathing, face, anthropometry.

\section{Summary}

\begin{abstract}
B reathing is responsible for facial and cranial morphology development. Aim: investigate in order to see if there is any relationship between oral breathing and facial type. Material and Methods: 119 male and female teenagers, with ages ranging between 15 and 18 years. The sample was separated in two groups: A-50 teenage oral breathers, 28 males and 22 females; and group B- 69 teenage nasal breathers, 37 males and 32 females. The sample was collected at the Centro de Atendimento e Apoio ao Adolescente do Departamento de Pediatria da UNIFESP/ EPM. We evaluated breathing and facial measures. Results: by means of anthropometric indexes we classified facial types and associated them with the person's breathing type, Hypereuriprosopic (Total $=0$; oral breathers $0 \%$; nasal breathers 0\%; Euriprosopic (Total $=14$; oral breathers $2.52 \%$, nasal breathers 9.24\%; Mesoprosope (Total=20; oral breathers 19.32\%; nasal breathers 21.01\%, Leptoprosopic (Total=37; oral breathers 14.29\%; nasal breathers 16.81\%; Hyperleptoprosopic (Total $=48$; oral breathers $5.89 \%$ nasal breathers $10.92 \%)$. The mesoprosopic facial type was found in 48 teenagers (40.33\%) of whom 25 (21.01\%) were oral breathers and $23(19.32 \%)$ were nasal breathers. Conclusion: it was not possible to prove the existence of an association between oral breathing and facial type.
\end{abstract}

${ }^{1}$ Master's degree, speech therapist.

${ }^{2}$ Doctoral degree, assistant professor of Human Communication Disorders, Speech Therapy Department, Sao Paulo Federal University.

${ }^{3}$ Doctoral degree, assistant professor of Human Communication Disorders, Speech Therapy Department, Sao Paulo Federal University. Address for correspondence: Ana Paula Bianchini - Rua Brasílio Machado 330 Santo André SP. Tel. (0xx11) 9356-6853.

Paper submitted to the ABORL-CCF SGP (Management Publications System) on March 3rd, 2006 and accepted for publication on March 31 th, 2006. cod. 1757. 


\section{INTRODUCTION}

Normal breathing is nasal, making it possible for inhaled air to be purified, filtered, warmed and humidified before reaching the lungs. Nose breathing protects the upper airways and is responsible for adequate craniofacial development.

Mouth breathing may result from upper airway obstruction or from habit wherein air flows through the mouth. According to the literature, this form of breathing may change the growth pattern of the face and lead to morphological and functional alterations in the whole organism.

Certain authors, such as Moccelin \& Ciuff (1997) ${ }^{1}$, Marchesan (1998) $)^{2}$, Lusvarghi (1999) ${ }^{3}$ and Di Francesco (1999), ${ }^{4}$ have defined mouth breathers as those persons with half-open, dry and cracked lips, an anteriorized tongue, weak mandibular elevator muscles, a deep and narrow palate, dental alterations and predominantly vertical face growth.

Altered facial growth in mouth breathers has been studied by various health care professionals, including medical doctors, speech therapists and orthodontists.

Anthropometry is that part of anthropology that investigates the body measurements. Cephalometrics is that part of anthropometry that studies the linear measurements and angles of the head.

Indices are used in anthropology to describe sizes regardless of absolute values. The facial morphological index is the centesimal ratio between the morphological height and width. This index classifies faces as leptoprosopic - long and narrow face; euryprosopic - wide and short face; and mesoprosopic - balanced facial width and height. (Avila, 19585).

The aim of this study was to verify a possible relation between mouth breathing and the facial type, to ascertain the validity of statements in the literature describing mouth breathers as having a long face.

\section{MATERIAL AND METHOD}

We assessed 119 male and female adolescents aged between 15 and 18 years. The sample was divided into two groups: group A - 50 mouth-breathing adolescents, 28 male and 22 female, and group B - 69 nose-breathing adolescents, 37 male and 32 female. The sample was obtained from the Adolescent Clinic and Support Center of the Pediatrics Department, UNIFESP/ EPM.

Adolescents that had genetic syndromes, malformation of the mouth and face, mental disability, cranial trauma, mutilation and dental anomalies of number and or size were excluded from the study.

The type of dental occlusion was not taken into account.

The mouth-breathing group contained adolescents that had mixed or mouth breathing.

Subjects underwent phonoaudiological assessments that consisted of the following steps:

I) a clinical history

II) a clinical phonoaudiological test.

I) Clinical history:

The clinical history was taken from the participant and/or the caretaker to obtain identification data (name, age, sex, race) and information about respiratory conditions such as rhinitis, sinusitis, asthma, bronchitis, frequent colds, tonsillitis, daytime and/or nighttime mouth breathing and nighttime snoring.

II) Clinical phonoaudiological test:

The clinical test was composed of the following steps:

A - Assessment of breathing.

Based on direct observation of the resting position and on tests.

A1 - Lip position of rest, classified as open or closed. Open was when the patient's lips did not touch and when muscular effort was required for contact between the upper and lower lip, a position that was not maintained for long.

A2 - Breathing was also assessed by filling the mouth with water; if the patient was unable to keep the mouth closed for at least three minutes, he or she would be considered a mouth breather. This test was supplemented by observation made during other clinical tests and by information obtained directly from the patients. (Vieira, 1986').

A3 - An Altman's nasal breath mirror (in millimeters), placed below the nostrils, was used to assess the presence and symmetry of nasal airflow. Patients were instructed to breathe normally for a few seconds, after blowing their noses.

B) Assessment of the face

The facial index, the relation between facial height and width, was calculated to find the facial type. Measurements were taken directly from the face of each adolescent.

Subjects were seated with their hips, knees and ankles at $90^{\circ}$ for the clinical test. Feet were flat on the ground, the spine was erect and touching the back of the chair. The head was oriented according to Frankfurt's plane, parallel to the horizontal plane and with its median sagittal plane perpendicular to the horizontal plane.

The facial height, or the length of the anatomical face, was measured as a straight line from the nasion to the gnathion. The nasion is the cephalometric point on the midline of the face that is located on the nasofrontal suture. The gnathion is the most anterior and inferior point on the suture of the mentum along the midline of the face; it may be palpated in living persons.

The facial width, the distance between the most 
laterally projecting points of the zygomatic arch, was measured between the right and left zygions. It may be established in living persons.

Facial height and width were measured in millimeters using a Mitutoyo model 500143 B digital pachymeter to which a $9 \mathrm{~cm}$ and $10 \mathrm{~cm}$ metal piece was attached on the external tips to make it possible for the rods to measure the facial height and width (zygions).

The facial proportion was obtained from the facial index or morphological facial index, which was based on these measurements. The facial index or morphological facial index is the centesimal relation between the height and width of the face, as follows:

\begin{tabular}{|ll|}
\hline Facial Morphological Index $=$ & Facial height $\quad$ X 100 \\
\cline { 2 - 2 } & Bizygomatic diameter \\
\hline
\end{tabular}

This index is used to classify the facial types, as follows: hypereuryprosopic - X-78.9; euryprosopic - 79.083.9; mesoprosopic - 84.0-87.9; leptoprosopic - 88.0-92.9; hyperleptoprosopic - 93.0-X. (Avila, 19585).

The UNIFEST/EPM Research Ethics Committee approved this study (protocol number 0738/03) and subjects signed a free informed consent form.

\section{RESULTS}

The hypereuryprosopic facial type was not found in our facial frequency study of male and female mouth and nose breathing groups. The most frequent facial type in males was the hyperleptoprosopic face, found in 33 adolescents (27.73\%). In females, the most frequent facial type was the leptoprosopic face, found in 16 adolescents $(13.45 \%)$. This difference is statistically significant, at $\mathrm{p}=0.008(\mathrm{p}<0.05)($ Table 1$)$.

The relation between facial types and the type of breathing revealed that the mesoprosopic face was the most frequent facial type, found in 25 mouth breathers (21.01\%) and in 23 nose breathers (19.32\%) (Table 2).

The relation between facial types and mouth and nose breathing in females showed that the leptoprosopic face was the most frequent facial type in nose breathers (10 subjects - 18.52\%) and the hyperleptoprosopic face was the most frequent facial type in mouth breathers $(9$ - 16.66\%) (Table 3).

The relation between facial types and mouth and nose breathing in males showed that the hyperleptoprosopic face was the most frequent facial type in both nose breathers (19 adolescents - 29.23\%) and mouth breathers (14 adolescents - 21.53\%) (Table 4).

A comparative analysis between mouth and nose breathing groups based on Dunnett's test 7 found no predominance of one facial type over any other (Table 5).
Table 1. Facial type's frequence of occurrence in nasal and oral breathing males and females.

\begin{tabular}{lcccccc}
\hline & \multicolumn{3}{c}{ Gender } & & \multicolumn{2}{c}{ Total } \\
\hline \multirow{2}{*}{ Face } & \multicolumn{2}{c}{ Female } & \multicolumn{2}{c}{ Male } & \multicolumn{2}{c}{ № } \\
\cline { 2 - 8 } & № & $\%$ & № & $\%$ & № & 0 \\
\hline Hypereuriprosopic & 0 & 0 & 0 & 0 & 0 & 0 \\
Euriprosopic & 11 & 9,24 & 3 & 2,52 & 15 & 1,76 \\
Mesoprosopic & 12 & 10,08 & 8 & 6,73 & 20 & 16,80 \\
Leptoprosopic & 16 & 13,45 & 21 & 17,65 & 37 & 31,10 \\
Hyperleptoprosopic & 15 & 12,61 & 33 & 27,73 & 48 & 40,34 \\
\hline Total & 54 & 45,38 & 65 & 54,62 & 119 & 100 \\
\hline
\end{tabular}

Table 2. Facial types frequence of occurence in oral and nasal breathing.

\begin{tabular}{lcccccc}
\hline & \multicolumn{3}{c}{ Breathing } & & \multicolumn{2}{c}{ Total } \\
\cline { 2 - 8 } Face & № & $\%$ & № & $\%$ & № & $\%$ \\
\hline Hypereuriprosopic & 0 & 0 & 0 & 0 & 0 & 0 \\
Euriprosopic & 11 & 9,24 & 3 & 2,52 & 14 & 11,76 \\
Mesoprosopic & 25 & 21,01 & 23 & 19,32 & 48 & 40,33 \\
Leptoprosopic & 20 & 16,81 & 17 & 14,29 & 37 & 31,10 \\
Hyperleptoprosopic & 13 & 10,92 & 7 & 5,89 & 20 & 16,81 \\
\hline Total & 69 & 57,98 & 50 & 42,02 & 119 & 100 \\
\hline
\end{tabular}

Table 3. Facial type's frequence of occurence in oral and nasal breathing in females.

\begin{tabular}{lcccccc}
\hline & \multicolumn{3}{c}{ Breathing } & & \multicolumn{2}{c}{ Total } \\
\hline \multirow{2}{*}{ Face } & № & $\%$ & № & $\%$ & № & $\%$ \\
\hline Hypereuriprosopic & 0 & 0 & 0 & 0 & 0 & 0 \\
Euriprosopic & 8 & 14,81 & 3 & 5,55 & 11 & 20,37 \\
Mesoprosopic & 8 & 14,81 & 4 & 7,4 & 12 & 22,23 \\
Leptoprosopic & 10 & 18,52 & 6 & 11,11 & 16 & 29,62 \\
Hyperleptoprosopic & 6 & 11,12 & 9 & 16,66 & 15 & 27,78 \\
\hline Total & 32 & 59,26 & 22 & 40,74 & 54 & 100 \\
\hline
\end{tabular}

Table 4. Facial type's frequence of occurence in oral and nasal breathing in males.

\begin{tabular}{lcccccc}
\hline & \multicolumn{3}{c}{ Breathing } & & \multicolumn{2}{c}{ Total } \\
\hline \multirow{2}{*}{ Face } & № & $\%$ & № & $\%$ & № & $\%$ \\
\hline Hypereuriprosopic & 0 & 0 & 0 & 0 & 0 & 0 \\
Euriprosopic & 3 & 4,61 & 0 & 0 & 3 & 4,61 \\
Mesoprosopic & 5 & 7,70 & 3 & 4,61 & 8 & 12,31 \\
Leptoprosopic & 10 & 15,39 & 11 & 16,93 & 21 & 32,31 \\
Hyperleptoprosopic & 19 & 29,23 & 14 & 21,53 & 33 & 50,77 \\
\hline Total & 37 & 56,93 & 28 & 43,07 & 65 & 100 \\
\hline
\end{tabular}


Table 5. Comparative analysis between groups $\mathrm{A}$ and $\mathrm{B}$ as far as facial type classification according to gender is concerned.

\begin{tabular}{|c|c|c|c|c|c|c|c|c|c|c|}
\hline \multicolumn{11}{|c|}{ Breathing } \\
\hline \multirow{3}{*}{ Face } & \multicolumn{4}{|c|}{ Nasal } & \multicolumn{4}{|c|}{ Oral } & & \\
\hline & \multicolumn{2}{|c|}{ Female } & \multicolumn{2}{|c|}{ Male } & \multicolumn{2}{|c|}{ Female } & \multicolumn{2}{|c|}{ Male } & \multicolumn{2}{|c|}{ Total } \\
\hline & № & $\%$ & № & $\%$ & № & $\%$ & № & $\%$ & № & $\%$ \\
\hline Hypereuriprosopic & 0 & 0 & 0 & 0 & 0 & 0 & 0 & 0 & 0 & 0 \\
\hline Euriprosopic & 8 & 14,8 & 3 & 4,6 & 3 & 5,6 & 0 & 0 & 14 & 11,8 \\
\hline Mesoprosopic & 8 & 14,80 & 5 & 7,70 & 4 & 7,40 & 3 & 4,60 & 20 & 16,80 \\
\hline Leptoprosopic & 10 & 18,5 & 10 & 15,4 & 6 & 11,1 & 11 & 16,9 & 37 & 31,1 \\
\hline Hyperleptoprosopic & 6 & 11,1 & 19 & 29,2 & 9 & 16,7 & 14 & 21,5 & 48 & 40,3 \\
\hline Total & 32 & 59,3 & 37 & 56,93 & 37 & 40,7 & 28 & 43 & 119 & 100 \\
\hline
\end{tabular}

\section{COMMENTS}

The investigation of facial types in mouth and nose breathing males and females showed that there were 33 male hyperleptoprosopic adolescents (27.73\%) and 16 female leptoprosopic adolescents (13.45\%). The X2 test revealed that there was a statistically significant difference between sexes (Table 1).

Our results are similar to those published by Gross, Kellum Hale et al. (1989). ${ }^{8}$ In their comparison between females and males they found the long face in $38.5 \%$ of their male subjects and in $30.9 \%$ of their females subjects out of a sample containing 133 subjects.

The study of facial types in mouth breathers showed that the mesoprosopic face was the most frequent facial type in 23 adolescents (19,32\%) (Table 2).

These findings are similar to those of Ferreira (1999), ${ }^{9}$ who also found that a higher proportion of his mouth-breathing subjects had the mesoprosopic face (5 patients - 44\%). Our findings are also similar to those of Sabatosk \& Maruo (2002) 10 and Aidar, who "found 18 mesoprosopic facial types in a study of mouth breathers (40.90\%)" (personal communication*).

Our results disagree with those of Mattar (2002) ${ }^{11}$ who found a correlation between facial morphology and the type of breathing; in this study, mouth breathers (84.68\% subjects) were predominantly dolichofacial and nose breathers were mostly mesofacial (88.07 subjects).

Our results also disagree with those of Harterink \& Vig (1989), ${ }^{12}$ Fields, ${ }^{13}$ Mocellim \& Ciuff (1997), ${ }^{1}$ and Manganello (2002) ${ }^{14}$ who state that the mouth-breathing habit could change the face and muscle balance, resulting in a higher rate of the long face (*Aidar L, Mota J, Marins C. 2004, personal communication).

Investigation of the face type in nose breathers revealed that there were 25 mesoprosopic adolescents
(21.01\%), ${ }^{20}$ leptoprosopic adolescents (16.81\%), 13 hyperleptoprosopic adolescents (10.92\%) and 11 euryprosopic adolescents (9,24\%) (Table 2).

These results are similar to those of Jabur (1997), ${ }^{15}$ who found a balance in the distribution of patients with vertical growth (9 subjects $-39.13 \%)$ and patients with a harmonic pattern (10 subjects - 43.47\%). Our results also agree with those of Vig, Sarver, Hall and Warren (1981), ${ }^{16}$ who found normal facial proportions and labial competence in 10 subjects (35.71\%).

A higher frequency of the mesoprosopic facial type in mouth breathers was not expected; in the literature many authors, such as Tourne (1990) ${ }^{17}$ and Mocellin \& Ciuff (1997), ${ }^{1}$ have stated that there is a relation between the long face and mouth breathing. According to these authors, mouth breathers keep their mouths constantly open and the tongue in a lowered position, without exerting pressure on the palate, resulting in external compression of the maxilla by the external muscles of the mouth. The hard palate tends to deepen, forming an ogival palate. The palate puts upward and forward pressure on the cartilaginous septum, causing its deviation and the elongated and narrowed face.

Investigation of the face type frequency in female nose and mouth breathers revealed that there were 10 leptoprosopic adolescents (18.52\%) and 9 hyperleptoprosopic adolescents (16.66\%) (Table 3).

In males, the hyperleptoprosopic face was the most frequent facial type in both nose breathers (19 adolescents - 29.23\%) and mouth breathers (14 adolescents - 21.53\%) (Table 4).

We were unable to compare these results with the literature, as we found no published papers describing the frequency of facial types in adolescents for each sex.

A comparative analysis between the nose-breathing group and the mouth-breathing group, based on the 
analysis of variance and Levene's test 7 at $\mathrm{p}<0.001$, revealed different means. We therefore applied Dunnett's test,7 enabling us to compare the mean facial indices; we found no frequency differences between facial types (Table 5).

Our results agree with those of Linder Aronson (1970),18 who found a low frequency of adenoid patients with an increased facial height (25.9\%).

These findings are different from those published by authors that used different methods, such as Mocellin \& Ciuff (1997)1 and Hartgerink, Vig (1989). ${ }^{12}$ Their results suggested that mouth breathing influenced facial form in $58.4 \%$ of their patients that were labially incompetent, and $56.2 \%$ of their patients that were labially competent. Manganello, Silva and Aguiar (2002) $)^{14}$ found that $40 \%$ of mouth breathers had an increased facial height. Principato (1986)19 concluded that $67 \%$ of his orthodontic patients had an abnormal growth of the lower facial height and increased nasal resistance to the passage of air.

Our findings are also different from those of Jabur et al. (1997), 15 who found an increased frequency of patients with a vertical growth pattern and mouth breathing (9 subjects - (39.13\%) and 10 patients (43.47\%) with a harmonic pattern.

\section{FINAL COMMENTS}

Based on our findings we were unable to demonstrate a relation between mouth breathing and increased facial height. We thus agree with Bhat \& Enlow (1995) ${ }^{20}$ and Kluemper $(1995)^{21}$ who in their papers showed that there is individual, genetic and regional variation.

There is much controversy about whether mouth breathing leads to the long face syndrome. Many clinicians believe that delayed growth of the dentofacial complex is the result of environmental and genetic forces. Recent findings suggest that mouth breathing by itself is not necessarily harmful for growth. Some hereditary patterns may favor mouth breathing compared to others. Mouth breathing in a subject with a genetic propensity for excessive vertical facial growth may be a complicating factor for developing undesirable forms of malocclusion. Current literature and longitudinal studies on respiratory function and the development of the craniofacial complex are being reviewed. Some studies show little evidence that altered breathing would affect craniofacial morphology.

Further studies are needed in this area of knowledge.

\section{CONCLUSION}

- We found no relation between mouth breathing and facial type.

- We found no statistically significant difference in the frequency of facial types in nose and mouth breathers.

- The mesoprosopic type was the most frequent facial type found in the current study; it was present in 25 adolescents (21.01\%) of the mouth-breathing group, and in 23 adolescents (19.32\%) of the nose-breathing group.

\section{REFERENCES}

1. Moccelin L, Ciuff, CV. Alteração oclusal em respiradores bucais. J Bras Ortod Ortop Maxilar 1999;2:47.

2. Marchesan IQ. Aspectos clínicos da motricidade oral. In: Fundamentos em fonoaudiologia. Rio de Janeiro: Guanabara Koogan;1998. p.23-36.

3. Lusvarghi L. Identificando o respirador bucal. Rev APCD 1999;53(4):14-19.

4. Di Francesco RC. Respirador bucal: a visão do otorrinolaringologista. J Bras Fonoaudiol 1999;1:56-60.

5. De Avila JB. Antropologia racial In: Antropologia física: Introdução. Rio de Janeiro: Agir; 1958. p.147-60.

6. Vieira MM. Da influência da deglutição atípica sobre os resultados do tratamento ortodôntico da mal-oclusão dental [tese de mestrado]. São Paulo: Escola Paulista de Medicina; 1986.

7. Rosner B. Fundamentals of biostatistics. 2o ed. Boston: Duxburry Press; 1986.

8. Gross AM, Kellun MGD, Hale EMCD et al. Myofunctional and dentofacial Relationships in second grade children. Angle Orthod 1989;60(4):247-53.

9. Ferreira ML. A incidência de respiradores bucais em indivíduos com oclusão Classe II. J Bras Ortod Ortop Facial 1999;21:223-40.

10. Sabatoski CV, Maruo H, Camargo ES, Oliveira JHG. Estudo comparativo de dimensões craniofaciais verticais e horizontais entre crianças respiradoras bucais e nasais. J Bras Ortod Ortop Facial 2002;7(39):246-57.

11. Mattar SEM. Padrão esquelético e características oclusais de crianças respiradoras bucais e nasais [tese de mestrado]. Ribeirão Preto: Universidade de São Paulo; 2002.

12. Hartgerink DV, Vig PS. Lower anterior facial height and lip incompetence: do not predict nasal airway obstruction. Angle Orthod 1989;59(1):17-22.

13. Fields HW, Warren DW et al. Relationship between vertical dentofacial morphology and respiration in adolescentes. Am J Orthod Dentofacial Orthop 1991;99(2):147-54.

14. Manganello LC, Silva AAF, Aguiar, MB. Respiração bucal e alterações Dentofaciais. Rev Assoc Paul Cirur Dent 2002;56(6):419-22.

15. 14. Jabur LB, Macedo AM, Craveiro LH, Nunes MM. Estudo clínico da correlação entre padrão respiratório e alterações ortodônticas e miofuncionais. Rev Odontol UNICID 1997;9(2):105-17.

16. Vig PS, Sarver DM, Hall DJ, Warren DW. Quantitative evaluation of nasal airflow in relation to facial morphology. Am J Orthod 1981;79(3):263-72.

17. Tourne PML. The long face syndrome and impairment of the nasopharyngeal airway. Angle Orthod 1990;60(3):167-76. 
18. Linder-Aronson S. Adenoids: their effect on mode of breathing and nasal airflow and their relationship to characteristics of the facial skeleton and the dentition. Acta Otolaryngol Suppl. 1970;265:5-132.

19. Principato JJ, Kerrigan JP, Wolf P. Pediatric nasal resistance and lower anterior vertical face height. Otolaryngol Head Neck Surg 1986;95 (2):226-9.
20. Bhat M, Enlow DH. Facial variations related to headform type. Angle Orthod 1985;55(1):269-80.

21. Kluemper GT, Vig PS, Vig KWL. Nasorespiratory characteristics and craniofacial morphology. Eur J Orthod 1995;17(1):4915. 